\title{
Neera- A Potential Natural Health Drink
}

\author{
Naveen Jose*1, Gajanan P Deshmukh ${ }^{2}$ and Menon Rekha Ravindra ${ }^{3}$ \\ ${ }^{1}$ M. Tech Scholar, ICAR- National Dairy Research Institute, India \\ ${ }^{2}$ Ph.D Scholar, ICAR-National Dairy Research Institute, India \\ ${ }^{3}$ Principal Scientist, ICAR- National Dairy Research Institute, India
}

Received: 制: November 21, 2018; Published: 跳: November 29, 2018

*Corresponding author: Naveen Jose, M. Tech Scholar, ICAR- National Dairy Research Institute, SRS, Bengaluru, India

\section{Introduction}

Growing health consciousness among the population in India has boosted the growth of health drinks industry in India. The segment has posted a healthy growth rate of around $40 \%$ in last few years, with a total turnover of more than Rs. 6.7 billion in 2008 . Players in the industry hope to maintain the strong growth rate. So far, the use of these kinds of drinks has not percolated to the mass market. Pricing as well as consumer awareness regarding the energy drinks remain the most critical factors for the success of health drinks in the country. Neera, also called palm nectar, is the phloem sap extracted from the inflorescence of various species of toddy palms which is used as a nutritious health drink. Neera is called sweet toddy since it contains zero percentage alcohol in it and is known as padaneer in Tamil Nadu. Toddy and Neera can be called as fermented sap and non-fermented sap. It is a refreshing and light drink, translucent in colour, extremely cool in sensation, sugary sweet to taste, similar to palm juice which is susceptible to natural fermentation at ambient temperature within a few hours of extraction due to enzymatic and microbial fermentation since it is rich in sugars, vitamins, proteins, minerals.

Once fermented, Neera becomes toddy which is unsuitable for health drink or for value added products. Neera is widely consumed in India, Sri Lanka, Africa, Malaysia, Indonesia, Thailand, and Myanmar. It is healthy and therapeutic drink since it is rich in Vitamin C, has more food calories than milk, fights diabetes, cancer, electrolyte deficiency and even hair fall. Neera is rich in sugar, essential elements such as N, P, K, Mg, micronutrients, minerals and a good source of ascorbic acid. It contains acids nicotinic acid (Vit B3) and riboflavin (Vit B2) and also can be consumed by people suffering from diabetes since it has a low glycemic index and a low glycemic load (Hebbar). Coconut sugar which is a byproduct of Neera, only possess a GI in the range of 35-45 per serving whereas refined white sugar possess 65-100 GI per serving (Swamy).
Reports suggests that Neera consumption prevents jaundice and also facilitates clear urination. It keeps the human system cool and improves digestion. Neera production is largely in an un-organized manner with major consumption by rural population and there is a wide scope for commercializing the product.

\section{Composition}

Neera is nearly neutral in $\mathrm{pH}$, with specific gravity ranging from 1.058-1.077. Several workers have studied the composition of palm sap Bassir, (1962), Chinarasa, (1968) Fararusi and Bassir, 1972; Okafor, 1978). The chemical percentage composition of Neera varies, depending on various factors, namely, place, type of palm, mode and season of its collection in Tables $1 \& 2$.

Table 1: The chemical percentage composition of Neera varies, depending on various factors.

\begin{tabular}{|c|c|}
\hline Substance & Concentration $\mathbf{( g / 1 0 0 ~} \mathbf{~ m L})$ \\
\hline Sucrose & $12.3-17.4$ \\
\hline Total ash & $0.11-0.41$ \\
\hline Protein & $0.23-0.32$ \\
\hline Ascorbic acid & $0.016-0.030$ \\
\hline Total solids & $15.2-19.7$ \\
\hline
\end{tabular}

Note: (Source- Indian Coconut Journal,2013).

Table 2: Biochemical and mineral composition of freshly collected Neera is given below.

\begin{tabular}{|c|c|}
\hline Biochemical parameters & Range \\
\hline $\mathrm{pH}$ & $6.57-7.50$ \\
\hline Total sugar $(\mathrm{g})$ & $10.08-14.50$ \\
\hline Reducing sugar $(\mathrm{g})$ & $0.439-0.647$ \\
\hline Amino acids & $0.123-0.338$ \\
\hline
\end{tabular}




\begin{tabular}{|c|c|}
\hline Sodium (mg) & $69.4-117.5$ \\
\hline Potassium (mg) & $146.1-182.4$ \\
\hline Phosphorous $(\mathrm{mg})$ & $2.0-6.4$ \\
\hline Manganese $(\mathrm{mg})$ & $0.009-0.014$ \\
\hline Copper $(\mathrm{mg})$ & $0.028-0.035$ \\
\hline Zinc $(\mathrm{mg})$ & $0.018-0.026$ \\
\hline Iron (mg) & $0.049-0.058$ \\
\hline
\end{tabular}

b) Neera Syrup: It is produced when fresh Neera is heated and concentrated into syrup and is used as a health and wellness drink in connection with Ayurveda and other systems of medicine [5].

c) Palm Wine (Toddy): It is an alcoholic beverage produced from the sap of palm which is mildly intoxicating and sweet, obtained by fermentation of natural yeasts yielding an aromatic wine having $4 \%$ alcohol content [6]. As the day progresses, it may yield a sourer, stronger and acidic product due to fermentation.

\section{Extraction}

Neera extraction is generally performed by tapping method collected from the inflorescence of coconut, which is done twice a day, both in the morning and evening. On an average, an adult coconut palm produces 12-14 inflorescences per year. The sap should be collected from a growing palm and the sweet sap is collected from the cut flower of palm by a tapper and a container is fastened to the flower to collect the sap. The sequential tapping and nut production technology (SCTNP) adoption can increase the farmer's income without sacrificing nut production as $3 / 4^{\text {th }}$ is tapped whereas $1 / 4$ is used for nut production. Usually it is collected in early morning at sunrise and as the day progresses, it will get converted into toddy which is alcoholic [1].

\section{Technological Developments in Preservation}

Neera is highly susceptible to natural fermentation at ambient temperature within a few hours of extraction from the palm source due to natural yeasts in air and once fermented, it transforms into toddy with $4 \%$ alcohol. Several technologies developed by various research institutes for processing and preserving the natural form of Neera and to retain the vitamins, sugar, and other nutrients beneficial for health. CPCRI has developed an equipment for easy collection and preservation of sap. To extend the shelf life of Neera, heat preservation techniques such as pasteurization are used which can extend the shelf life up to a week without much loss in its nutritive components [2]. It can be stored under refrigerated condition to arrest the growth of microorganisms and enzymatic reactions. A team of experts from SCMS Institute of Bio Sciences and Biotechnology, Cochin, India have successfully developed filtration and preservation techniques for Neera in collaboration with Coconut Development Board to commercialize the drink among the public [3]. National Chemical Laboratory in Pune has developed a special filtration technique to enhance the shelf life and Central Food Technological Research Institute in Mysore, India also developed technologies for the preservation and processing of Neera.

\section{By-products}

a) Coconut Jaggery: It is soli or semi-solid crystalline mass obtained by boiling and evaporating Neera in small batches with final product having $\mathrm{pH}$ in the range of 6.5-7.0 [4]. The production requires minimal heat treatment without the the aid of any additives or enzymes. Caramelization turns the heated Neera from milky white to transparent brown.

Spices are added to obtain distinct taste to product

d) Palm Honey: It is a thick liquid syrup similar to honey, having a sweetness of $78^{\circ}$ Brix and a pH of 6.0-6.5, which is used as sweetener in ice creams and other confectionaries. Palm honey also find applications in pharmaceutical formulations and is good for patients suffering from anemia as it is rich source of iron.

e) Palm Sugar: The coconut sap sugar is obtained by moderately heating the freshly harvested Neera at $115^{\circ} \mathrm{C}$ to remove water which is considered as one of the best natural sweetener since it has no added chemicals. It is widely used as sweetener in SouthEast Asian regions since thousands of years which is a perfect and healthier substitute for artificial sweeteners. It is rich in minerals, vitamins and has twice the iron, four times the magnesium and over ten times the zinc than brown sugar which is obtained from sugar cane.

\section{Conclusion}

Chilled Neera is a healthy and thirst-quenching drink which gives a cool feeling to the body. The shelf life can be extended upto 45 days using scientific methods such as filtration, pasteurization and addition of preservatives so that the market reach of the product can be extended upto urban areas. It has been medically proved that Neera is better than mineral water and it also has less calorific value, apart from being sweet and delicious. Neera could become a nutritious drink offering a healthy alternative to aerated beverages if it is commercialized in a proper way.

\section{References}

1. Swamy, GM Siddharameswara (2013) Coconut Neera production and processing in Karnataka. Indian Coconut Journal.

2. Kumari, Anila, Anita Pandey, Anton Ann, Anup Raj, et al. (2016) Indigenous Alcoholic Beverages of South Asia.

3. Hebbar K, AC Mathew, Manivannan, Arivalagan, Kukkamgai, et al. (2013) Value added products from Neera. Indian Coconut Journal pp. 28-33.

4. Borse, Babasaheb Bhaskarrao, Lingamallu Jagan Mohan Rao, Kulathooran Ramalakshmi, Bashyam Raghavan, et al. (2007) Chemical composition of volatiles from coconut sap (neera) and effect of processing. Food chemistry 101(3): 877-880.

5. Baliga BP, AC Ivy (1961) Beverage preservation, pasteurization of palm sap (Neera) Journal of Agricultural and Food Chemistry 9(2): 149-151.

6. Bhagya D, Soumya Gopan (2016) Effects of coconut neera (Cocos nucifera L.) on blood pressure among hypertensive adult women International Journal of Applied and Pure Science and Agriculture 2: 1-7. 


\section{ISSN: 2574-1241}

DOI: 10.26717/BJSTR.2018.11.002114

Naveen Jose. Biomed J Sci \& Tech Res

(c) (P) This work is licensed under Creative

Submission Link: https://biomedres.us/submit-manuscript.php

$\begin{array}{ll}\text { BIOMEDICAL } & \text { Assets of Publishing with us } \\ \text { RESEARCHES } & \text { Global archiving of articles } \\ \text { - Immediate, unrestricted online access }\end{array}$

